a $\mathrm{p}$ value $<0.001$. The factors associated with bullying were the younger age group, shorter length of service, shifting work, non-managerial position and the designation as a doctor.

Conclusion A significant proportion of healthcare workers had been bullied, and bullying exposure was shown to be associated with depression and low self-esteem. Hence, regular screening for bullying, depression and low self-esteem should be done to enable early intervention.

\section{CHANGES IN TWENTY YEARS OF THE EPIDEMIOLOGICAL STATUS OF NEEDLESTICK/SHARPS INJURIES REPORTED TO JAPAN-EPINET THROUGH A NATION-WIDE SURVEILLANCE NETWORK}

1,2T Yoshikawa*, ${ }^{1} \mathrm{~K}$ Wada, ${ }^{1} \mathrm{JJ}$ Lee, ${ }^{1} \mathrm{~T}$ Mitsuda, ${ }^{1} \mathrm{H}$ Kuroshi, ${ }^{1} \mathrm{M}$ Aminaka, ${ }^{1} \mathrm{U}$ Morisawa, ${ }^{1} \mathrm{~K}$ Morikane, ${ }^{1} \mathrm{H}$ Kunishima, ${ }^{1} \mathrm{~K}$ Kidouchi, ${ }^{1} \mathrm{~K}$ Moriya. ${ }^{1}$ The Research Group for Occupational Infection Control and Prevention in Japan (JRGOICP); ${ }^{2}$ Research Centre of Overwork-Related Disorders (RECORDS), National Institute of Occupational Safety and Health (JNIOSH), Japan

\subsection{6/oemed-2018-ICOHabstracts.976}

Introduction This study aimed at examining annual logs of needlestick/sharps injuries (NSIs) collected through a voluntary nation-wide surveillance network in twenty-years for preventing occupational blood-borne infections. The emphasis was placed on revealing the past and current situations of NSIs in health care settings.

Methods Japan-EPINet format was developed by the technical support of the International Healthcare Worker Safety Centre, University of Virginia in the United States in 1996. Japan-EPINet Surveillance (JES) was conducted by the Research Group for Occupational Infection Control and Prevention in Japan (JRGOICP). Data were analysed in four phases of the nationwide surveillance network of AIDS referral hospitals out of a total of 364 registered, a total number of hospital-year was 1879. These hospitals reported employees' percutaneous injuries on a voluntary basis.

Results A total of 65,032 NSIs were reported to Japan-EPINet from 1996 to 2015. The rate of hepatitis C antibody positive cases of the total NSIs decreased from $69.9 \%(1,511 / 2,161)$ in 1996 to $11.5 \%(714 / 6,201)$ in JES2015. The proportion of NSIs due to 'recapping' decreased $(28.7 \%, 6.9 \%$ respectively). Devices caused to NSIs by winged steel needles $(25.3 \%$, $8.6 \%)$ and vacuum tube phlebotomy needles $(4.8 \%, 1.7 \%)$ were decreased, disposal syringe $(28.5 \%, 26.2 \%)$ and IV catheter $(6.7 \%, 5.2 \%)$ were fairly decreased. The proportion of Suture needle $(10.3 \%, 16.9 \%)$ and pre-filled cartridge syringe $(2.8 \%, 8.3 \%)$ were increased.

Discussion The changes of characteristics NSIs in Japan in twenty-year suggested that recognition of the risks of NSIs was vital for promoting the effective use of safety-engineered needle/sharp devices and point-of-use disposal containers because the rate of hepatitis $\mathrm{C}$ antibody positive cases among voluntary reported NSIs. The creation of the nation-wide surveillance network was effective for monitoring and evaluating NSIs and for focusing on implementation of effective countermeasures.
25 PREPARATION OF HAZARDOUS DRUGS IN BIOLOGICAL
SAFETY CABIN (BSC): THE CHALLENGE OF GETTING
HEALTHIER WORK ENVIRONMENTS

${ }^{1}$ MAmparo Benavent Benavent, ${ }^{2}$ MAmparo Ortuño Moreno. ${ }^{1}$ Hospital Clinic Universitari, Valencia, Spain; ${ }^{2}$ Hospital La Fe, Valencia, Spain

10.1136/oemed-2018-ICOHabstracts.977

Introduction Hazardous drugs are an important risk to health care workers. Some of these products may even be potentially carcinogenic.

In different Spanish hospitals it was observed that only Cytostatics drugs were prepared in biological safety cabins, leaving workers exposed to the rest of hazardous non cytostatic drugs.

Methods A bibliographical review of scientific articles and researches has been carried out, together with the laws on occupational health and recommendations of the Spanish organisms.

In the USA, research promoted the development of policies of prevention and the incorporation of these drugs in the list NIOSH.

Result After analysing the information obtained, we detected the following problems: HD's are prepared in hospitalisation rooms, where the right conditions to protect workers are nonexistent; In many cases, health care workers are given only personal protective equipment to avoid exposure; Specific health control isn't performed in most cases; National legislation obliges the risk to be taken into account for the worker. Although there are no long-term epidemiological studies, protective measures should be taken.

Discussion In many hospitals in our country HD's are not prepared in biological safety cabins. Health workers are unaware that they are exposed to these risks and no specific health training or monitoring is performed. Collaborative epidemiological researches should be promoted among Public Health Units, which have information on the prevalence rate of cancer diseases, and those responsible for occupational health prevention.

\section{HOW THE WORKING BACKS PROGRAMME HELPED STAFF MANAGE BACK PAIN, REMAIN IN WORK AND REDUCE ABSENTEEISM}

Bulfin Siobhan*, Tuohy Niamh, A Purcell, A O'Reilly. St. Vincent's University Hospital, Dublin, Ireland

\subsection{6/oemed-2018-ICOHabstracts.978}

Introduction The Working Backs Programme (WBP) is designed for staff reporting back pain as a result of work or whose work performance is affected. It's a comprehensive approach including medical assessment, provision of information and education, a designated physiotherapy and ergonomic staff referral service and a referral pathway for further investigations and/or review. The effectiveness was evaluated by an initial audit in 2012 and subsequent audits in 2015 and 2016. Methods Data was collected through questionnaires at initial consultation and post discharge for comparison. This included 
the quantitative tools: Patient Specific Functional Score (PSFS) self-reporting of functional ability to complete tasks and the Numerical Pain Rating Scale (NPRS) self-rating of pain score. A cross-sectional analysis of absenteeism rates was also performed to determine the percentage of WBP participants with certified absence and work hours lost for back pain.

Result In 2012, 75\% of participants found the WBP beneficial. This figure rose to $96 \%$ and $94 \%$ in 2015 and 2016 respectively.

In 2012, 52\% of participants achieved a 2 point increase or greater for their average score in the PSFS. In 2015 and 2016 it was $88 \%$ and $72 \%$ respectively. A 2 point change for the average score is valid to be $90 \%$ confident that a real improvement occurred.

In $201266 \%$ reported a reduction in pain levels on the NPRS. In 2015 and 2016 this increased to $96 \%$ and 92\%, respectively.

In 2012, 52\% of the WBP participants had some certified leave of absence for back pain. This decreased to $21 \%$ in 2015 and to $12 \%$ in 2016.

Work hours lost for back pain in 2012 was $2.5 \%$ of the total percent of absenteeism. This decreased in 2015 and in 2016 to $0.4 \%$ and $0.6 \%$ respectively (a reduction of $76 \%$ in back related absence in a four year period).

Discussion The WBP demonstrated both personal and organisational benefits. It has proven to be a worthwhile health promotion initiative. It's ethos is based on an active approach in the management of back pain, enabling staff to remain at work while effectively managing back pain.

\section{BARRIERS AND WORK IMPAIRMENT ASSOCIATED TO SICKNESS PRESENCE}

A Skerjanc, MD Fikfak. Clinical Institute for Occupational, Traffic and Sports Medicine, University Medical Centre Ljubljana, Slovenia

\subsection{6/oemed-2018-ICOHabstracts.979}

Introduction Sickness presence is a relatively new 'phenomenon that people, despite complaints and ill health that should prompt them to rest and take sick leave, go to work in any case'. The highest sickness presence is largely to be found in the care and welfare and educational sectors. The aim of the study is to investigate the relations between barriers and work impairment and sickness presence among health care workers.

Methods A cross-sectional study was conducted at the largest hospital in Slovenia involving 5865 health care workers employed at the University Medical Centre Ljubljana in the year 2010. Each employee obtained a questionnaire composed of three standardised international questionnaires. Logistic regression methods were used to assess the associations between risk factors and sickness presence. The questionnaire contained questions related to demographic factors and factors that describe one's own assessment of workability (absenteeism, barriers and work impairment, anticipated certainty about one's own workability in the following year). Data was analysed using SPSS.

Results In multivariate modelling the highest odds were calculated for barriers at work $(\mathrm{OR}=4,5 ; 95 \% \mathrm{CI}: 3,8$ to 5,3$)$, anticipated uncertainty about workability $(\mathrm{OR}=1,9 ; 95 \% \mathrm{CI}$ : $1,5$ to 2,3$)$, sickness absence more than twice a year $(\mathrm{OR}=3,6 ; 95 \% \mathrm{CI}: 3,0$ to 4,4$)$ and sickness absence more than twice in the past year $(\mathrm{OR}=2,7 ; 95 \% \mathrm{CI}: 2,2$ to 3,3$)$.
Conclusion This is the first surveillance on sickness presence indicates that besides the pre-requisite - bad health, sickness presence is associated with barriers at work, their consequences on behaviour of the workers and sickness absence. If continued they might have negative consequences on work and health care worker's health and require a response in health care organisation.

\section{TITLE CORRELATES OF PRESENTEEISM: A STUDY OF NURSES WORKING IN GERIATRIC SETTINGS IN MALTA}

L Fiorini* ${ }^{*}$ A Griffiths, J Houdmont. Institute of Mental Health. University of Nottingham, Nottingham, UK

\subsection{6/oemed-2018-ICOHabstracts.980}

Introduction Presenteeism is usually defined as attending for work while ill. It is linked with lost productivity and increased sickness absence, and can be costly to organisations. Studies suggest a high prevalence of presenteeism in the healthcare sector. Additionally European statistics suggest that presenteeism is particularly frequent in Malta (EU). A study was therefore conducted to investigate the correlates of presenteeism in a sample of nurses working within a geriatric ward setting in Malta.

Methods A cross-sectional survey $(n=270)$ investigated the suggested predictors of presenteeism that had emerged in an earlier qualitative study. Hierarchical binary logistic regression was used to identify the correlates of presenteeism. Data was analysed using SPSS.

Result Individuals who had engaged in presenteeism two or more times in the previous 12 months were more likely to have: engaged in sickness absenteeism frequently (OR 2.36, 95\% CI: 1.02 to 5.94); felt emotional during their last presenteeism episode (OR 1.21, 95\% CI: 1.07 to 1.37); felt that their last sickness absenteeism episode was good for their health (OR 1.72, 95\% CI: 1.14 to 2.61); and felt presenteeism was necessary following recent sick leave (OR 1.45, 95\% CI: 1.08 to 1.94$)$. They were also less likely to have: reported a fracture (OR $0.06,95 \% \mathrm{CI}: 0.01$ to 0.63 ) or gastric illness (OR $0.35,95 \% \mathrm{CI}: 0.15$ to 0.82 ) during their last absenteeism episode; understood the illness that led to their last presenteeism episode (OR 0.80, 95\% CI: 0.67 to 0.95 ); and to feel that they had managerial and peer support (OR $0.45,95 \%$ CI: 0.26 to 0.91 ).

Discussion The study highlights that presenteeism is linked to overall health, however perceptions of individual illnesses can also influence the frequency of this behaviour. The study also supports previous findings that work attitudes and organisational factors also play a role. Interventions that benefit nurses' health and provide support at work may reduce the frequency of presenteeism.

\section{DEVELOPMENT OF AN INTERVENTION TO FACILITATE RETURN TO WORK OF UK HEALTHCARE STAFF WITH COMMON MENTAL HEALTH DISORDERS}

${ }^{1}$ Dorota Juszczyk, ${ }^{2}$ Max Henderson, 'Vaughan Parsons, ${ }^{3}$ Julia Smedley, ${ }^{4}$ Robert Shannon, ${ }^{1}$ Ira Madan. 'Guy's And St. Thomas' NHS Foundation Trust, London, UK; ${ }^{2}$ St James University Hospital, Leeds, UK; ${ }^{3}$ Southampton University Hospitals NHS Trust, Southampton, UK; ${ }^{4}$ University of Southampton, Southampton, UK

10.1136/oemed-2018-ICOHabstracts.981 